\title{
Technical Efficiency of Agricultural Production in Ethiopia
}

\author{
Tsion Yohannis ${ }^{1} \quad$ Anbes Tenaye ${ }^{2}$ Zerhun Ganewo ${ }^{3}$ \\ 1.Department of Agricultural Economics, College of Agriculture and Natural Resource, \\ Jinka University, Ethiopia \\ 2.Department of Agricultural Economics, College of Agriculture, Hawassa University, Ethiopia P.box 05 \\ 3.Department of Agribusiness and Value Chain Management, College of Agriculture Hawassa University, \\ Ethiopia P.box 05
}

\begin{abstract}
Farmers faced low productivity due to lack of knowledge on maximizing level of output at the given level of inputs. Technical efficiency of agricultural production in the Ethiopia were assessed by using cross-sectional secondary data collected from Ethiopia socioeconomic survey in 2015/16 production year. Cobb-Douglas stochastic frontier production function model was used to estimate technology and determinants of technical inefficiency simultaneously using the maximum likelihood estimator (MLN). MLN estimation results showed that increasing input use like area, seed, oxen, fertilizer and labor would increase yield of agricultural production. The coefficients of elasticity for area, seed, oxen, fertilizer and labor were $0.21,0.29,0.38,0.12$ and 0.10 respectively. Consequently, agricultural production exhibits increasing return to scale because the sums of input elasticity's were greater than one which is 1.1 . The mean technical efficiency of farmers in the agricultural production was about $36 \%$. The implication is that there is an opportunity to increase output on average by $64 \%$ through efficient use of inputs given the current input use and technology. The discrepancy ratio gamma $(\gamma)$ which measures the relative deviation of output from the frontier due to inefficiency was about 86 percent indicating that about $86 \%$ of variation in agricultural production among the farmers was attributed to technical inefficiency effects. Thus, it is possible to improve technical efficiency through better use of these factors.
\end{abstract}

Keywords: Technical efficiency, Cobb-Douglas stochastic frontier and Smallholders.

DOI: $10.7176 / \mathrm{JNSR} / 10-5-05$

Publication date:March $31^{\text {st }} 2020$

\section{INTRODUCTION}

1.1. Background: Ethiopia is an agrarian country where about $43 \%$ of GDP and $85 \%$ of total employment is agriculture based (MoARD, 2010). Within agriculture, about $60 \%$ of agricultural GDP is derived from crop production whereas livestock and account $27 \%$, and other areas contribute $13 \%$ of the total agricultural value added. The sector is dominated by small-scale farmers who practice rain-fed mixed farming by employing traditional technology, adopting a low input and low output production system., respectively (Gebre-Selassie and Bekele, 2013). Because of the greater contribution of agriculture to the national economy, the government of Ethiopia has adopted the Agricultural Development Led Industrialization (ADLI) strategy as a national development strategy (Diao, 2010). The main goal of ADLI was to attain fast and broad-based development within the agricultural sector and to stimulate the overall development of the economy through the linkage effects of agriculture to other sectors (Diao, 2010).

In spite of its great importance to the country's economy, agricultural productions are however, subsistencebased and dominated by smallholder farm households that operate on farms of less than one hectare (GebreSelassie, 2004). Smallholder farming represents for about 90 percent of agricultural outputs and 95 percent of land area under crop production. In general, about 98 percent of coffee, the country's leading cash crop and 94 percent of food crops are produced by smallholders, while only 2 percent of coffee and 6 percent of crop production are produced by private and state commercial farms.

Technical efficiency of a producer is a comparison between observed and optimal values of its outputs and inputs. It refers to the ability to avoid wastage either by producing as much output as the optimal output given the technology and input use allow or by using as little input as required the given technology and output. Technical efficiency promotes output and conserves input as a main argument. The technical efficiency ranges between zero and one. TE values of 1 represents a producer is producing on its production frontier (technically efficient), and 1TE represents inefficiency (Musa et.al., 2014).

However, the agricultural productivity of Ethiopia remains low and the country is unable to match the food demand of the ever increasing population (IFAD, 2008). Low agricultural productivity of the country is commonly attributed to limited access of the smallholder farmers to agricultural inputs, financial services, improved production technologies, irrigation, agricultural markets, the prevailing poor soil and land management practices (IFAD, 2008).

1.2. Problem statement: In an agriculture dependent poor economy, it would be expected that growth in 
agricultural production, especially in crop production growth, would contribute more in reducing poverty than strong macro-economic growth (Boccanfuso and Kabore, 2004). Thus, the key to growth in agricultural production in Ethiopia lies in increasing productivity and efficiency of smallholder farmers (Owour, 2000). Substantial policy emphasis is given to the agricultural sector in Ethiopia because of the importance of agriculture in poverty alleviation, improving food security and in promoting overall economic development (Spielman, Kelemwork and Alemu, 2011).

Despite having abundant agricultural resource potential and following a consistent agricultural policy to boost agricultural productivity, the expected productivity increment was not achieved. The level of rural poverty is high and about $39 \%$ of the Ethiopian population still live below the poverty line measured by the percentage of the population living on less than the equivalent of US\$1.25 per day (UNDP, 2013). In the prevailing empirical studies of the Ethiopian smallholder's technical efficiency indicate the existence of technical inefficiencies. According to Wassie (2014) technical efficiency of major crop in Ethiopia found that variation in output due to technical inefficiency for teff, wheat and maize production to be $88.5,45.5$ and 77.8 percent respectively. Similarly according to Bachewe (2009) explored the sources of inefficiency and growth in agricultural output in subsistence agriculture in Ethiopia and obtained an average farm level technical efficiency of $40 \%$.

Measuring efficiency level of farmers benefit the growth of the country since it enables to raise productivity by improving the neglected source of growth with the existing resource base and available technology (Musa et.al, 2014). Analysis of technical efficiency could contributes to the identification of production constraints at farm level and there by improves the food security and income sources in the farm sector and the rest of economy. Therefore, the motivation behind this research was in-depth analysis of technical efficiency of cereals crops, root crop, vegetables, and fruit crops and livestock production in the Ethiopia

1.3. Objectives of the study: the overall objective of this study is to analysis technical efficiency of agricultural production in Ethiopia. Specific objectives were to: estimate the level of technical efficiency of agricultural production and identify factors affecting the variation in the level of technical inefficiency among smallholder farmers in Ethiopia agricultural production.

\section{RESEARCH METHODS AND MATERIALS}

2.1. Description of study area: Ethiopia is bordered by Eritrea to the North, Djibouti and Somalia to the East, Kenya to the South and the Republic of Sudan and the Republic of Southern Sudan to the West (Mengistu, 2006). At present, Ethiopia is structured into a federation of nine ethnic based administrative regions and two centrally chartered city administrations (Sori, 2009).

2.2. Data type and source: This study principally used Ethiopia socioeconomic survey (ESS) secondary data collected in 2015/16 which is 3rd round wave survey of CSA of Ethiopia and World Bank. The first wave was implemented in 2011/2012 and second round wave was implemented in 2013/2014.the data formed part of Ethiopia Socioeconomic Survey (ESS). The central statically agency of Ethiopia, collaboration with World Bank, conducted a living standard and agricultural survey in 2015/16. The purpose of survey was to obtain comprehensive agricultural, welfare and socio-economic information on rural and small town household in the country. Under the ESS, CSA used two-stage probability sample, the first stage of sampling entailed selecting primary sampling units, which are a sample of the CSA enumeration areas (EAs). A survey a total of 433 EAs were selected based on probability proportional to size of the total EAs in each region. For the rural sample, 290 EAs were selected from the AgSS (Annual Agriculural Sample Survey) EAs. A total of 43 and 100 EAs were selected for small town and urban areas, respectively. The second stage of sampling was the selection of households to be interviewed in each EA. For rural EAs, a total of 12 households are sampled in each EA. Of these, 10 households were randomly selected from the sample of 30 households. The households are households which are involved in farming or livestock activities. Another 2 households were randomly selected from all other non-agricultural households in the selected rural EA (those not involved in agriculture or livestock). In some EAs, there is only one or no such households, in which case, less than two non-agricultural households were surveyed and more agricultural households were interviewed instead so that the total number of households per EA remains the same.

The Central Statistics Agency of Ethiopia employed questionnaire based on personal interview to collect the data from 3,451 households in the first wave. During the second wave 3,1255 households were re-interviewed yielding a response rate of 85 percent. Attrition in urban areas is $15 \%$ due to consent refusal and inability to trace the where about of sample households (CSA and World bank, 2015/16).

\subsection{Model specification}

The data was analyzed by using both descriptive and econometric methods. The descriptive statistics (mean, percentage, and standard deviation) and econometric model, stochastic production frontier (SPF) model through STATA version 13 was used to obtain the maximum likelihood estimate of parameters for both the technology 
and inefficiency, simultaneously. To detect multicollinearity, the Variance Inflation Factor (VIF) and contingency coefficients (CC) were conducted

\subsubsection{Estimating technical efficiency using stochastic frontier analysis}

Technical efficiency measurements have to do with the comparison of actual performance to optimal performance. The estimation of technical efficiency comprises two main methods, namely, the parametric approach and the nonparametric approach. However, this study was employed the parametric approach. An example of the parametric approach is the stochastic frontier approach. The stochastic frontier function, an improved model of estimating technical efficiency was developed independently by Aigner, Lovell and Schmidt (1977) and Meeusen and van de Broeck (1977).

\subsubsection{Production Frontier Model Specification}

The production frontier specified using different functional forms such as linear, quadratic, Cobb-Douglas, Trans $\log$ and Leontief (Coelli et al., 2005: 211). Functional forms are commonly determined by requirements such as flexibility of the functional forms, the general conformity and adequacy of the models in explaining a given data and on theoretical bases hypothesized to adopt a specific functional form (Griffin et al., 1987). The uses of CobbDouglas and Trans log functional forms dominate applications of production frontier literature (Fried et al., 2008: 98).

\subsubsection{Technical inefficiency model specification}

In order to identify and analyze the determinants of technical efficiency, a technical inefficiency model was employed. In the technical inefficiency model, the dependent variable is the technical inefficiency variable $\left(U_{i}\right)$ and the explanatory variables are the factors that are hypothesized to affect technical inefficiency $\left(\mathrm{Z}_{\mathrm{i}}\right)$. A positive sign of a coefficient of a technical inefficiency model parameter implies that the variable considered has an increasing effect on technical inefficiency and vice versa. The implication of the relationship is that variables that increase technical inefficiency will decrease technical efficiency Battesse and Coelli(1995.

\section{RESULTS AND DISCUSSION}

\subsection{Descriptive statistics}

This section includes both descriptive and econometrics results. The first section starts by describing descriptive part followed by econometrics result.

\subsubsection{Demographic variables}

This section presents the profile of the sample respondents with regard to their demographic characteristics like age, sex, and household size. The purpose of understating those variables is to know the decision making environment within which agricultural production are undertaken. The average year of household head was 48 with standard deviation 15.06 and the maximum years were 98 , the lowest begin 13 years. This indicates as the most of sampled farmers found in active and energetic age category and they are considered as economically active force to perform its works effectively and efficiently. The average of household size in labor force unit was 6 persons per family with standard deviation 2.6, minimum and maximum was 1 and 18 respectively, means that the number of active labor force from the interviewed household ranges from one to eighteen persons. Regarding the Sex of household head, 73.72 percentages of sampled households were male while remaining 26.28 percentages were female farmers (Table 2). This implies that the agricultural production is dominated by male in Ethiopia. This may be because female are responsible for the care and maintenance of the household and its members, including bearing and caring for children, preparing food, collecting water and fuel, housekeeping and family health-care than agricultural activity. Even if male and female involved in productive activities, their responsibilities and functions often differ.

Table 2: Descriptive statistics for demographic characteristics

\begin{tabular}{lrrrr}
\hline Variable & Mean & Std. Dev. & Min & Max \\
\hline AGEHH & 47.66 & 15.06 & 13 & 98 \\
HHSIZE & 6.13 & 2.63 & 1 & 18 \\
\hline Descriptive statics for dummy variable & & Frequency & Percentage \\
\hline Sex of household head & Male & & 2544 & 73.72 \\
& Female & & 907 & 26.28 \\
\hline
\end{tabular}

Source: own computation (2018)

\subsubsection{Socioeconomic variables}

The average total livestock holding in tropical livestock unit sampled households was about 4 tropical livestock unit. Off-farm income is very important for contributing production of agricultural products in Ethiopia. The only 9.16 percent of sampled farmers were obtained off-farm income activity participant while the remaining 90.84 percent of farmers had no access to off-farm income activity in the Ethiopia (Table 3). This shows that the farmers had less participation to off-farm income generating activities. 
Table 3: Descriptive statistics for socio-economic variables

\begin{tabular}{lllll}
\hline Variables & Mean & Std. dev & Min & Max \\
\hline Livestock in TLU & 4.13 & 5.40 & 0 & 58.82 \\
Education al status of head & 0.04 & 0.58 & 0 & 12 \\
\hline Dummy economic variable & \multicolumn{3}{c}{ Frequency } & Percentage \\
\hline Participation on off-farm income & Yes & 316 & 9.16 \\
& No & 3135 & 90.84 & \\
\hline
\end{tabular}

Source: Own computation, 2018.

Education HH: - Education, measured in years of schooling, the average year of schooling was 4 with standard deviation 0.58 and ranging from 0 up to 12 (Table 3). This shows that some sampled farmers are not attending formal education while some of others attending their education from lower grade up to above certificate different parts of country.

\subsubsection{Agricultural production or output}

The dependent variable which is output used in production function measured by the monetary value which means, it is not sold production but all of crop production changed in to $\mathrm{Kg}$ and livestock production (meat, eggs, milk, cheese and butter) multiplied by their respective price that was set by the community level in the data of ESS 2015.Therefore the average income of household from both crops and livestock was 54,671.84ETB with standard deviation 183713.9 and average value of livestock production was 3107.738 ETB with standard deviation 14093.33. The average value of total crop production was 51564.1ETB with standard deviation 183182.8. The reason for why the minimum value of both the crop and livestock production is zero, because the data of 2015/16 interviewed farmers respond that in the harvesting season they were asked like question whether they harvest or not in the production season. If they harvest the product put the amount of production and if not harvest by the interviewed time put zero value on the amount of production.

\subsubsection{Input variables}

The total amount of seed used for crops production which included seed obtained purchased, received by loan and free. According to (Table 5) the seed used for crops production the average value of total seed used $71.52 \mathrm{~kg}$, with standard deviation 96.59. Ownership of oxen of the respondents during the production season can cause performance variation. The average number of oxen is 0.85 with standard deviation 1.28 and the minimum and maximum number was 0 and 14, respectively. Fertilizer is primary input for crops production. Farmers used different combinations of fertilizer, including chemical, organic, combinations of chemical and organic or neither. In the (Table 5) the average amount of total chemical fertilizer (DAP and Urea) used during main season was $66.25 \mathrm{~kg}$ with standard deviation 265.03

Table 5: Descriptive statistics for input variables

\begin{tabular}{lllll}
\hline Variables & Mean & Std. Dev. & Min & Max \\
\hline Total seed in Kg & 71.52 & 96.59 & 0.002 & 1150 \\
Oxen owned TLU & 0.83 & 1.27 & 0 & 14 \\
Fertilizer in Kg & 66.25 & 265.03 & 0 & 5000 \\
Labor in adult equivalent & 2.41 & 1.22 & 0.2 & 9.8 \\
Land owned in hectare & 1.05 & 1.66 & 0.00058 & 29.04
\end{tabular}

Source: Own computation, 2018.

The land is common input for crops and livestock the average size of area allocated for both crops and livestock production was $1.05 \mathrm{hr}$ with lowest and largest area of 0.00058 and $29.04 \mathrm{hr}$ respectively, with standard deviation 1.66. The average labor utilized 2.4 with standard deviation of 1.22 while the minimum labor used in adult equivalent was 0.2 , the maximum 9.8 .

\subsubsection{Farming management}

The variables depicted in (Table 6) are dummy variables used in the inefficiency model. The result presented in Table 6 show that the majority of farmers are have fertile or good soil 89.34 percent and infertile or poor soil 10.66 percent. This implies that most of farmers have good practices to conserve the soil quality in Ethiopia and quality of soil and 10.66 percent which are poor or low quality of soil.

Table 6: Descriptive statistics for farming management

\begin{tabular}{llll}
\hline Variables & Response & Frequency & Percentage \\
\hline Soil fertility & Fertile (good) & 3083 & 89.34 \\
& Infertile (poor) & 368 & 10.66 \\
Irrigation access & Yes & 309 & 8.95 \\
& No & 3142 & 9.05 \\
Seed type & Improved & 2710 & 78.53 \\
& Traditional & 741 & 21.47 \\
\hline
\end{tabular}

Source: Own computation, 2018. 
Irrigation is a means supplying sufficient water for better crop production. Among the total sampled respondents 8.95 percent of farmer was used irrigation water and most of farmers 91.05 percent interviewed were not used irrigation water in Ethiopia. This implies as majority of farmers depended on rain fed agriculture. Farmers had choice to use traditional and improved seed. The majority of Ethiopian farmers 78.53 percent were use improved seed while only 22.47 percent of farmers were used traditional seed. This implies that most of them are used improved seed rather than traditional seed.

\subsection{Result of econometrics analysis}

In this section ML estimation of production function, efficiency score and determinants of inefficiency variables are presented and discussed clearly. Estimation of production frontier: In this study, five input variables were used for estimation of the frontier production function which includes the land area allocated to agricultural production in hectare, number of oxen power utilized in farming, seed in kilogram, fertilizer used expressed in kilogram and labor utilized in adult equivalent while twelve inefficiency variables associated with agricultural production were included in the model. These include age in years, education level in year of schooling, household size in labor force unit, irrigation use ( 1 if yes, 0 otherwise) access to extension ( 1 if yes, 0 otherwise), credit access ( 1 if yes, 0 otherwise), size of land holding in hectare, livestock in tropical livestock unit, sex ( 1 if male, 0 female), access to off-farm income ( 1 if accessed, 0 otherwise), seed type( 1 if improved, 0 traditional) and soil fertility ( 1 fertile and 0 , otherwise).

A one-stage estimation procedure was employed to analyze the technology and inefficiency model simultaneously. One of the important features of single-stage estimation procedure is it guarantees that the distributional assumption of inefficiency error term is not violated. Due to this reason, one- stage estimation procedure was preferred to two-stage estimation procedure which violates the assumption of distribution of error term (Battese and coelli, 1995).

The estimate of Cobb-Douglas production function based on truncated-normal distribution is presented in (Table 5). The result shows that from five input variable four are significant except labor. Seed, oxen, fertilizer and area input variables are significant at one 1\% significant level and positive coefficient. The coefficient of area, seed, oxen, fertilizer and labor were $0.21,0.29,0.38,0.12$ and 0.10 respectively. The all these inputs except labour have statically significant and positive contribution to level of output, means that an increase of all these inputs would increase agricultural output. The sum of the estimated coefficients is 1.1 , indicating increasing return to scale in agricultural production in the Ethiopia. This result is in line with Wassie (2014) land, fertilizer and seed were found to have significant and positive effect in major crop production in Ethiopia. Accordingly, Mohammed et al. (2015) and Hailemaraim (2015) explain that fertilizer is an important input in increasing production and productivity level of agricultural crops.

The sum of regression coefficients exceeds, less than and equal to one said to be increasing return to scale, decreasing return to scale and constant return to scale respectively. The higher elasticity of input variables would have greater impact in determining the level of output while lower elasticity of input variables would have lower impact in influencing level of output.

The elasticity of oxen is very high implying oxen have greater impact in determining agricultural production. Consequently, agricultural production in Ethiopia needs high amount of oxen for land preparation. The reason is as we know in Ethiopia the agricultural system is not as much developed by modern technology, means most of farmers used oxen power rather than tractor or machine because of economic capacity. Therefore, oxen have high contribution for production as well as economically. Coefficients of seed and area have relatively higher impacts in determining production level of farmers output as elasticity shows.

The other parameter estimated is gamma $(\gamma)$ used to show the proportion of total variance that is attributed to technical inefficiency in the estimated model. The value of gamma was 0.86 . The value of gamma implies that $86 \%$ the random variation in agricultural production is attributed to the technical inefficiency component which indicates the importance of capturing technical inefficiency in production. From the calculated value of $\gamma$ at the truncated-normal models, it indicates that about 14 percent of random variation in agricultural production is attributed random shock that is out of the control of framers in Ethiopia. 
Table 8: Estimation of frontier production function

\begin{tabular}{lccc}
\hline Variables & Coefficient & Std. Err & P-value \\
\hline Constant & 8.93 & 0.14 & $0.000^{* * *}$ \\
AREA & 0.21 & 0.03 & $0.000^{* * *}$ \\
SEED & 0.29 & 0.03 & $0.000^{* * *}$ \\
OXEN & 0.38 & 0.08 & $0.000^{* * *}$ \\
FERTZ & 0.12 & 0.02 & $0.000^{* * *}$ \\
LABOR & 0.10 & 0.07 & 0.195 \\
\hline Sigma U & 4.01 & 0.12 & $0.000^{* * *}$ \\
Sigma V & 1.62 & 0.03 & $0.000^{* * *}$ \\
Lambda & 2.48 & 0.21 & $0.000^{* * *}$ \\
\hline
\end{tabular}

$\operatorname{sigma}^{2}\left(\sigma^{2}\right)=\sigma_{u}^{2}+\sigma_{v}^{2}=17.7$ Mean $\mathrm{TE}=0.36$

$\operatorname{Gamma}\left(\gamma=\lambda^{2} /\left(1+\lambda^{2}\right)=0.86\right.$ Number of obs $=3,451$ Loglikelihood

Source: Own computation (2018). ***, stands for significance at levels of $1 \%$.

The mean technical efficiency of household is 0.36 in SFA model. In fact, technical efficiency is a relative concept and these values imply that farmers on average 36 percent efficient compared to the most efficient farmer in the respective model. In general, the values are consist with the study by Asefa (2012), Geta et al. (2013), Tirkaos(2013) and Abebe(2014).

\subsubsection{Estimation of household specific technical efficiency}

The estimated mean technical efficiency of agricultural production output of farmers was about 36 ranging between 0.015 and 81 percent indicating that there is room to boost famer's level technical efficiency through using input variables and currently available technology. This implies that the farmers can increase the level of agricultural production on average by about 64 percent without incurring additional production inputs in Ethiopia. The presence of technical inefficiency in a production indicates potential output gains without increasing the level of factors of production. In other way round, had the average farmers been operating to achieve their most efficient level farmers, $55.1 \%$ (i.e. $1-[36 \% / 81 \%]$ ) cost saving would have been realized by the agricultural output producer farmers in the study area. Similarly, if the most inefficient farmers in the sample were to achieve the technical efficiency level of their most efficient fellow farmers then they would certainly save $99.98 \%(1-[0.015 \% / 81])$ cost. Furthermore, of the sampled farmers, results indicated that there was no fully efficient farmer in agricultural production in sample farmers of Ethiopia, confirming that given the level of production factors and technologies, there is still room for improvement in agricultural productivity.

As indicated in the Table 9, when technical efficiency scores category in percent went up, the number of farmers included in each category decreased to show an inverse relationship. Out of the total sample, 38.16 and 0.03 farmers in the sample were the highest and lowest number of respondents included in 40-60 (highest) and >80\% (lowest) efficiency score category respectively.

\subsubsection{Determinants of technical inefficiency}

Before making interpretation, understanding the sign of inefficiency parameters is very important. Negative sign of inefficiency parameters shows that the variable reduces technical inefficiency or positively affects technical efficiency while positive sign shows increase technical inefficiency or decrease technical efficiency. After knowing this, it is necessary to go to discussion and interpretation of variables that affect technical inefficiency. Twelve inefficiency variables were presented in (Table 10).

The result shows that sex, livestock, household size, extension service and seed type were negatively related with technical inefficiency while only off-farm income participation was positively related with technical inefficiency. Off-farm income: The estimated coefficient of off-farm income shows a positive and significant association between off-farm income technical inefficiency and negative relationship with technical inefficiency production. According to Amare (2005), off-farm incomes can have positive effect on the households' efficiency by alleviating financial constraints in terms of timely purchase of farm inputs. On the other hand, participating in off-farm activities might be at the expense of own farm activities in terms of less labor and time causing for a negative relationship between technical efficiency and participation in off-farm activities. This implies that an increase in off-farm income participation increases the technical inefficiency of farmers and increase technical inefficiency and decrease technical efficiency. This result related with Singh, et al. (2009) and Geta, et al. (2013) who found negative correlations; and Chang and Wen (2011) who confirmed differential effects of participation in off-farm activity on technical efficiency of farm household.

Livestock: The coefficient of livestock in tropical livestock unit is negative and significant at $1 \%$ significance level and it is decrease the technical inefficiency of production and increase technical efficiency of production. This might be because livestock provides manure as fertilizer, cash to finance input expenses and draught power. This result is similar with the study by Beshir et al. (2012) and (Wudineh and Endrias, 2016).

Sex: The sex of the household head is significantly negative at $1 \%$ level of significance as was expected, indicating 
that male headed households operating more efficiently than their female counterparts. This result is in line with the study by Tiruneh and Geta (2016) and Kibaara and Kavoi (2012).

Table 10: Determinants of technical inefficiency variables

\begin{tabular}{llll}
\hline Variables & Coefficient & Std. Err & P-value \\
\hline Constant & 0.96 & 0.04 & $0.000 * * *$ \\
AGE & -0.01 & 0.01 & 0.509 \\
EDU & 0.12 & 0.20 & 0.543 \\
OFFFARM & 2.41 & 0.48 & $0.000^{* * *}$ \\
SOILF & -.91 & 0.66 & 0.165 \\
ACCCT & -.12 & 0.89 & 0.893 \\
TLU & -.90 & 0.13 & $0.000^{* * *}$ \\
FARMS & 0.06 & 0.31 & 0.856 \\
EXT & -4.69 & 1.14 & $0.000^{* * *}$ \\
IRR & -.86 & 1.01 & 0.395 \\
SEEDT & -9.7 & 0.82 & $0.000^{* * *}$ \\
SEX & -1.22 & 0.39 & $0.002 * * *$ \\
HHS & -.35 & 0.08 & $0.000^{* * *}$
\end{tabular}

Source: own computation $(2018) * * *$ stands for significance at $1 \%$ respectively.

Extension: Extension is a dummy variable that was hypothesized to influence technical inefficiency of agricultural production negatively. The empirical result indicates that extension has a negative and highly significant coefficient. Extension therefore decreases technical inefficiency as expected. The possible reason for the result is that farmers who obtained extension services can have better information about farm management practices and better agricultural technologies. The finding is supported by Obwona (2006) and Bachewe (2009) who acknowledged the importance of extension services as a key policy instrument to improve agricultural productivity. Household size: The number of family size in the household has a positive and highly significant impact on technical inefficiency at five percent level of significance. A possible reason for this result might be that a larger household size guarantees availability of family labor for farm operations to be accomplished in time. At the time of peak seasons, there is a shortage of labor and hence household with large family size would deploy more labor to undertake the necessary farming activities like ploughing, weeding and harvesting on time than their counterparts and hence they are efficient in crop production. This result similar with positive and significant impact of household size on efficiency was found by Aye and Mungatana (2010) and Shumet (2011) in their respective studies.

Seed type: in this study farmers use either improved seed or traditional seed, the variable of seed type is included as a dummy variable to determine if the use of improved seed decreases technical inefficiency. The coefficient of seed is negative and significant at one percent significant level it indicts the use farmer use improved seed used rather than traditional seed, the level of technical inefficiency would be decreasing. The finding is consistent with the empirical studies of Geta et al. (2010) and Maseatile (2011) where the use of improved seed increases technical efficiency of agricultural production.

\section{Conclusion and Policy Implications}

Stochastic frontier production function was used to analyze technical efficiency of agricultural production in Ethiopia by using secondary data from Ethiopia socioeconomic survey (ESS) conducted 2015/16 CSA in collaboration with World Bank. Cobb-Douglas stochastic frontier model was used to estimate the production technology, and technical efficiency and its determinants simultaneously using one-stage estimation procedure. The SFA is more appropriate than convectional production function (ordinarily least square) because it includes inefficiency. The existence of inefficiency component in the error term can be tested in the case of SFA unlike DEA. Accordingly, the $\gamma$ value of at truncated-normal distributions was 0.86 for the agricultural production function can be then interpreted as, $86 \%$ of the variation in output among household is explained by technical inefficiency. SPF model incorporates 17 variables in addition to composite error term $\left(\mathrm{V}_{\mathrm{i}}\right.$ random error term associated with noise and $\mathrm{U}_{\mathrm{i}}$ non-negative random variable associated with inefficiency effects), of which 5 variables are input variables while remaining 12 variables are variables associated with inefficiency effects.

Result of the frontier production function indicates that except labor four input variables (Area, seed, oxen and fertilizer) were found to be positive and significant at one percent significant level, meaning that an increase in one of inputs will enhance production keeping everything constant. Generally, except labor all significant input variables were found to affect output positively, as expected. Oxen has highest elasticity which was affect agricultural production, followed by seed, area, and fertilizer with value of $0.21,0.29,0.38,0.12$ and 0.10 respectively and the sum of coefficient was 1.1 implying that increasing return to scale.

The inefficiency effect analysis for agricultural production shown that sex, livestock, household size, seed type and extension service were negatively influence technical inefficiency and off-farm were positively related 
with technical inefficiency and negatively related with technical efficiency in Ethiopia. However, soil fertility, irrigation use, farm size, age of household head, education and access of credit were insignificant. The mean technical efficiency of farmers in the production of agricultural production was found to be $36 \%$ ranging between $0.015 \%$ and $81 \%$. This shows that there is possible potential to improve technical efficiency of farmers with the currently available technology and input level.

An important conclusion from this study is that smallholder farmers in Ethiopia are inefficient so that, there was a considerable room to reduce the level of technical inefficiency of agricultural production in Ethiopia without additional input use. Alternatively, input requirements of producing the average output can be reduced if these farmers' operation becomes technically efficient, which is true for smallholder farmers in Ethiopia and in other developing countries.

\section{REFERENCES}

Amare, H. 2005. Analysis of technical efficiency in sorghum production: The case of smallholder farmers in RayaAzebo district, Southern Tigray, Ethiopia. An M.Sc. Thesis presented to the School of Graduate Studies of Haramaya University, Ethiopia.

Bachewe, F.N. 2009. The State of Subsistence Agriculture in Ethiopia: Sources of Output Growth and Agricultural Inefficiency. PhD Thesis. Faculty of Graduate School. University of Minosota, USA.

Baruwa, O.I. \&Oke, J.T.O. 2012.Analysis of the Technical Efficiency of Smallholder Cocoyam Farms in Ondo State of Nigeria.Tropicultura, 30(1):36-40.

Battese, G.E. \&Coelli, T.J.1995 .A Model for Technical Inefficiency Effects in a Stochastic Frontier Production Function for Panel Data. Empirical Economics, 20, 325-332.

Boccanafuso, D. \& Kabore, T.S. 2004 .Macroeconomic Growth, Sectoral Quality of Growth and Poverty in Developing Countries: Measure and Application to Burkina Faso.Working Papers No 04-07. Sherbrook. Canada.

Central Statistical Agency (CSA). 2011. Ethiopian Demographic and Health Survey. Addis Ababa. Ethiopia.

Central Statistical Agency (CSA). 2012. Agricultural Sample Survey Report on Area and Production of Major Food Crops: Private Peasant Holdings. Meher Season. Addis Ababa. Ethiopia.

Coelli, T.J., Prasada, R.D., O’Donnell, C.J. \&Battese, G.E.2005.An Introduction to Efficiency and Productivity Analysis. $2^{\text {nd }}$ ed. New York: Springer Science + Business Media.

Deressa, T. T. 2007. Measuring the economic impact of climate change on Ethiopian agriculture: Ricardian approach. World Bank Policy Research Working Paper (4342).

Diao, X.2010. Economic Importance of Agriculture for Sustainable Development and Poverty Reduction: The Case Study of Ethiopia. A paper presented to the Working Part on Agricultural Policy and Markets. Paris, France, 17-20 May 2010.

Dercon, S. \& Hill, R.V .2009. Growth from Agriculture in Ethiopia: Identifying Key Constraints. Paper Prepared as Part of the Study on Agriculture and Growth in Ethiopia Addis Ababa. Ethiopia.

FDRE (Federal Democratic Republic of Ethiopia). 2015. The Second Growth and Transformation Plan (GTP II) (2015/16-2019/20) (Draft).National Planning Commission,AddisAbaba.Pp26-27.

Fried, H.O., Lovell, C.A.K. \& Schmidt, S.S. 2008. The Measurement of Productive Efficiency and Productivity Growth. Oxford: Oxford University Press.

Gebre-Selassie, A. \&Bekele, T. 2013.A Review of Ethiopian Agriculture: Roles, Policy and Small-scale Farming Systems: Country Analysis. Addis Ababa, Ethiopia.

Geta, E., Bogale, A., Kassa, B., \& Elias, E. 2013. Productivity and efficiency analysis of smallholder maize producers in Southern Ethiopia. Journal of Human Ecology, 41(1): 67-75.

Gujarati, Damodar N. 2003. Basic Econometrics: Fourth Edition, the McGraw- Hill Companies, Inc., New York.

International Fund for Agricultural Development (IFAD). 2008. Enabling Poor Rural People to Overcome Poverty. Federal Democratic Republic of Ethiopia, Country Strategic opportunities Programme. Note to Executive Board Directors for Review. Rome. Italy.

Ministry of Agriculture and Rural Development (MoARD).2010. Ethiopia's Agricultural Sector Policy and Investment Framework Draft Final Report. Addis Ababa. Ethiopia.

Mengistu, A.2006. Country Pasture/Forage Profile: Ethiopia. Offic of Knowledge Exchange, Research and extension. FAO. Rome. Italy.

Musa H. Ahmed, Lemma Z., Endrias G. 2014. Technical Efficiency of Maize Producing Farmers in ArsiNegelle, Central Rift Valley of Ethiopia: Stochastic Frontier Approach. Journal Agriculture \& Forestry, Vol. 60 Issue 1: 157-167, 2014, Pp 157-167.

Owuor, J. 2000. Determinants of Agricultural Productivity in Kenya: Kenya Agricultural Marketing and Policy Analysis Project. Tegemeo Kenya Agricultural Research Institute. Michigan State University.

Rachev, Svetlozar T.; Höechstöetter, Markus; CFA,Frank J. Fabozzi; Focardi, Sergio M. .2007., Probability and Statistics for Finance, John Wiley \& Sons publisher, USA. 
Schmidt, P. 1986. Frontier Production Functions. Econometric Reviews, 4, 289-328.

Shumet, A. 2011. Analysis of technical efficiency of crop producing smallholder farmers in Tigray, Ethiopia. [Internet]. Munich Personal RePEc Archive (MPRA) Paper No. 40461.Available from: http://mpra.ub.unimuenchen.de/40461/

Sori, A.T. 2009. Profile of Religious Experience in Ethiopia. Seminar Paper Presented at Religious Pluralism and Public Presence in the US Summer Institute. Department of Religious Studies. University of California. Santa Barbara.

Spielman, D.J., Kelemwork, D. \& Alemu, D. 2011.Seed, Fertilizer and Agricultural Extension in Ethiopia. ESSP II Working Paper No 20. International Food Policy Research Institute. Addis Ababa. Ethiopia.

United Nation Development Organization (UNDP).2013. Human Development Report: The Rise of the South. hdr.undp.org/en/media/HDR2013_EN_Statistics.pdf.

Wassie, S.B. 2012. Application of Stochastic Frontier Model on Agriculture: Empirical Evidence in Wheat Producing Areas of Amhara Region, Ethiopia. [Internet]. BoD - Books on Demand publishing, Germany.

Wudineh Getahun and Endrias Geta. 2016. Technical Efficiency of Smallholder Wheat Farmers: The case of Welmera district of Central Oromia, Ethiopia. Journal of Development and Agricultural Economics, 8(2):3951 